\title{
Immunoaffinity Purification of Protein Complexes from Mammalian Cells
}

\author{
Chieri Tomomori-Sato ${ }^{1}$, Shigeo Sato ${ }^{1}$, Ronald C. Conaway ${ }^{1,2}$, and Joan W. Conaway ${ }^{1,2,3}$ \\ ${ }^{1}$ Stowers Institute for Medical Research, 1000 E. 50 ${ }^{\text {th }}$ Street, Kansas City, MO 64110 \\ ${ }^{2}$ Department of Biochemistry \& Molecular Biology, Kansas University Medical Center, Kansas \\ City, KS 66160
}

\begin{abstract}
In this chapter, we describe a purification scheme designed to isolate multisubunit protein complexes gently and quickly from crude extracts of mammalian cells using immunoaffinity purification of epitope tagged proteins and the multisubunit complexes with which they associate. As an example we describe isolation of the mammalian Mediator complex from HeLa S3 cells.
\end{abstract}

\section{Keywords}

Multisubunit protein complex; Immunoaffinity purification; Epitope tag; Stable cell line

\section{Introduction}

\begin{abstract}
Many functions in gene regulation are carried out by multi-subunit complexes that can be composed of anywhere from a few to dozens of different protein subunits. Experiments to define the composition and function of such complexes require the ability to isolate intact, functionally active complexes from tissues or cultured cells. Classical, conventional chromatography-based purification strategies separate proteins or multi-subunit complexes from one another based on differences in physico-chemical properties such as size, charge, or hydrophobicity. While conventional chromatography-based approaches have long been used for protein purification, they suffer from a number of disadvantages. First, many multiprotein complexes are quite fragile and are not stable to the extremes of ionic strength or other conditions encountered during ion exchange, hydrophobic interaction, gel filtration, or other forms of conventional chromatography. Second, the degree of purification that can be obtained using any one separation method is typically limited, and it is almost always necessary to develop time-consuming and technically challenging strategies that combine multiple purification steps.
\end{abstract}

The use of immunoaffinity purification strategies can alleviate many of the problems associated with conventional chromatography. In an immunoaffinity purification, an antibody that recognizes a protein of interest is bound to a resin such as agarose or Sepharose beads. A cell extract or partially purified fraction is passed over the antibodyresin, unbound proteins are washed away, and specifically bound proteins are then eluted from the antibody with competing epitope peptides or by more harsh treatments that result in complex dissociation or loss of activity, such as high salt or brief exposure to acidic $\mathrm{pH}$. Using such methods, it is possible to achieve substantial purification in a single step;

\footnotetext{
${ }^{3}$ Corresponding author. jlc@ @stowers.org.
} 
however, successful application of immunoaffinity approaches is dependent on the availability of antibodies with suitable affinity and specificity.

It is often not possible to obtain antibodies suitable for immunoaffinity purification for each individual protein that one wishes to study. An alternate strategy takes advantage of wellcharacterized antibodies that recognize short, defined peptide sequences with high specificity and affinity. These sequences, referred to as "epitope tags," are added to either the amino- or carboxyl-terminus of a protein of interest (1). When expressed in mammalian cells, the epitope tagged protein can be incorporated into a protein complex or complexes in place of its endogenous counterpart, allowing purification of the tagged protein and any proteins with which it is associated by immunoaffinity chromatography using anti-epitope antibodies (See Note 1). Table 1 shows a list of commonly used epitope tags for immunoaffinity purification (2-5).

A general strategy for the use of epitope-tagging and immunoaffinity purification of protein complexes is outlined in Figure 1. The first step is to construct a suitable expression vector that encodes an epitope tagged protein that can be expressed in mammalian cells. The second step is to generate and amplify clonal cells stably expressing useful amounts of the epitope tagged protein. Finally, the protein of interest and any associated proteins can be purified from nuclear or cytoplasmic extracts by single-step immunoaffinity purification by binding to immobilized anti-epitope antibody and competitive elution with epitope peptides. Using this approach, we have successfully used anti-FLAG epitope immunoaffinity purification to purify the human Mediator of RNA polymerase II to near homogeneity from extracts of HeLa S3 cells stably expressing any of a large number of FLAG-epitope tagged Mediator subunits (6) (Figure 2). Notably, using cell lines expressing FLAG-tagged versions of mutant Mediator subunits, we have been able to purify mutant Mediator complexes that have proven useful in functional studies (7).

\title{
2. Materials
}

\subsection{Production of Mammalian Cell Lines}

Host cells (e.g. HeLa S3 cells, HEK293/FRT cells)

Expression vector encoding epitope-tagged protein of interest

Antibiotic needed for drug selection of stably transformed cells

\subsection{Cell Extract Preparation}

\author{
0.4\% (w/v) Trypan Blue Solution in PBS (\#25-900-Cl, Mediatech)
}

Hypotonic buffer (10 mM HEPES (pH7.9), $1.5 \mathrm{mM} \mathrm{MgCl}_{2}, 10 \mathrm{mM} \mathrm{KCl}, 0.5 \mathrm{mM}$ Dithiothreitol)

Extraction buffer (20 mM HEPES (pH7.9), $1.5 \mathrm{mM} \mathrm{MgCl}_{2}, 0.6 \mathrm{M} \mathrm{KCl}, 0.2 \mathrm{mM}$ EDTA, $0.5 \mathrm{mM}$ Dithiothreitol, 25\% Glycerol)

Phosphate buffered saline

Buffer C (20 mM HEPES (pH7.9), 1.5mM $\mathrm{MgCl}_{2}, 0.2 \mathrm{mM}$ EDTA, $0.5 \mathrm{mM}$

Dithiothreitol, 25\% Glycerol)

Protease inhibitor (P8340, SIGMA), add to all buffers immediately before use

\footnotetext{
${ }^{1}$ Epitope tags at one or the other end of a protein of interest can sometimes prevent complex assembly and/or be sterically occluded. Accordingly, it is advisable to generate both amino- and carboxyl-terminally tagged versions of the protein of interest.
} 
Dounce homogenizer ( $40 \mathrm{ml}, 15 \mathrm{ml}$, and/or $7 \mathrm{ml}$ )

15 and $50 \mathrm{ml}$ conical plastic tubes

$1.5 \mathrm{ml}$ microcentrifuge tubes

Beckman type JS4.2 or similar rotor

Beckman J6 or similar centrifuge

Beckman type 45Ti rotor and ultracentrifuge

Polycarbonate ultracentrifuge bottles (\#355622, Beckman)

Variable speed motorized tube rotator

\subsection{Immunoaffinity Purification}

Equilibration buffer (50 mM HEPES (pH7.9), $1.5 \mathrm{mM} \mathrm{MgCl}_{2}, 50 \mathrm{mM} \mathrm{KCl}, 0.3 \mathrm{M}$ $\mathrm{NaCl})$

Washing buffer (50 mM HEPES (pH7.9), $1.5 \mathrm{mM} \mathrm{MgCl} 2,300 \mathrm{mM} \mathrm{NaCl}, 10 \mathrm{mM} \mathrm{KCl}$, $0.2 \%$ TritonX-100)

Elution base buffer (50mM HEPES (pH7.9), $0.1 \mathrm{M} \mathrm{NaCl}, 1.5 \mathrm{mM} \mathrm{MgCl}_{2}, 0.05 \%$

TritonX-100)

Elution buffer (Elution base buffer with 200 or $500 \mu \mathrm{g} / \mathrm{ml}$ of epitope peptide)

Protease inhibitor cocktail (P8340, SIGMA); should be added to all buffers at 1:100 dilution immediately before use

Beckman type Ti70.1 rotor and ultracentrifuge

Polycarbonate ultracentrifuge tubes (\#355630, Beckman)

15 and $50 \mathrm{ml}$ conical plastic tubes

$1.7 \mathrm{ml}$ low binding microcentrifuge tubes (\#3207, Corning Costar)

Glass fiber pre-filter disc (Millex-AP, \# SLAP02550, Millipore)

Sepharose 4B

Micro Bio-Spin ${ }^{\circledR}$ chromatography columns (\#732-6204, Bio-Rad)

Poly-Prep ${ }^{\circledR}$ chromatography columns (\#731-1550, Bio-Rad)

Adams $^{\mathrm{TM}}$ Nutator or similar mixer

FLAG epitope: Anti-FLAG M2 affinity gel (A2220, SIGMA), FLAG peptide (F3290, SIGMA), 3x FLAG peptide (F4799, SIGMA)

HA epitope: Anti-HA agarose (clone HA-7, A2095, SIGMA), HA peptide (I2149, SIGMA)

cMyc epitope: Anti-cMyc agarose (sc-47694AC, Santa Cruz), cMyc peptide (M2435, SIGMA)

V5 epitope: Anti-V5 agarose (A7345, SIGMA), V5 peptide (V7754, SIGMA)

\section{Methods}

\subsection{Production of cell lines expressing epitope tagged proteins}

To purify a multisubunit protein complex it is first necessary to establish a cell line that stably expresses an amino- or carboxyl-terminally epitope tagged protein. Detailed protocols 
for generating such cell lines have been provided elsewhere (8), so here we provide only a brief outline.

The choice of cell line and gene transfer method will depend on the specific experimental purpose; however, we often use HeLa S3 cells (CCL-2.2 $2^{\mathrm{TM}}$ ATCC), which can be grown in suspension and are therefore advantageous when it is desirable to perform large-scale purifications. We have had good success using constitutive protein expression systems. Occasionally, however, we use a tetracycline inducible expression system, such as the Flp$\mathrm{In}^{\mathrm{TM}} \mathrm{T}-\mathrm{Rex}{ }^{\mathrm{TM}}$ Mammalian Expression System (Invitrogen), when the protein of interest is toxic and either kills cells or is expressed at particularly low levels when expressed constitutively. While it is possible to use mixed populations of stably transformed cells, we typically generate clonal cell lines because they can usually be grown for many passages without loss of protein expression.

Prior to attempting to generate stable cell lines, we first confirm that the desired protein can be expressed from the expression vector following transient transfection into HEK293T or other easily transfectable cells. Protein expression can be evaluated by western blotting of whole cell lysates using antibodies directed against the epitope and/or native protein. Lysates from transiently transfected cells can also be used in anti-epitope immunoprecipitations followed by western blotting if the level of expression is too low to be detected by western blotting of lysates and/or to confirm that the epitope is useful for immunoprecipitation.

Once the utility of the expression vector has been confirmed, it is introduced into the desired cell line using plasmid-based or virally-mediated gene transduction (Table 2), and stably transformed cells are selected and cloned using the appropriate drug selection (see Note 2) and screened for expression of the desired protein using western blotting and/or immunoprecipitation. Frozen stocks of cloned cell lines are prepared, and cells are amplified for further purification and analysis (see Notes 3).

\subsection{Preparation of nuclear and cytosolic (S100) extracts}

Below is the general procedure we use to prepare extracts from 12 liter suspension cultures of HeLa S3 cells expressing FLAG-epitope tagged Mediator subunits. Additional protocols are provided elsewhere (9-11). Keep all buffers and equipment cold on ice, and perform the following procedures in a $4^{\circ} \mathrm{C}$ cold room if available.

1. Count cells using a hemocytometer, and evaluate cell viability using Trypan-blue staining; when observed under the microscope, dead or lysed cells will stain blue. Use cells with $>95 \%$ viability.

2. Transfer cells from culture flasks to $1 \mathrm{~L}$ centrifuge bottles and spin $5 \mathrm{~min}$ at 1500 $\mathrm{rpm}$ in a Beckman J6 centrifuge using a type JS4.2 rotor at $4^{\circ} \mathrm{C}$.

\footnotetext{
${ }^{2}$ Commonly used expression vectors carry genes encoding resistance to antibiotics (e.g. hygromycin, neomycin/G418, or puromycin); hence, the choice of antibiotic for selection of stably transformed cells is determined by the specific expression vector being used. Optimal antibiotic concentrations for selection of drug-resistant, stably transformed cells will vary with the specific cell line used. Before proceeding to stable cell line production, we recommend generating a "kill curve" to define the lowest concentration of antibiotic that will kill all non-transformed cells. To do so, culture parental cells in media containing various concentrations of the selection antibiotic. Observe the cells daily and determine the percent viable cells. We use the minimum concentration of selection antibiotic needed to kill all parental cells 6-8 days after placing cells under drug selection.

${ }^{3}$ Even with initially clonal populations of cells it is possible to observe changes in expression level or even mutation of the exogenously expressed cDNA when cells are grown in culture for a long period of time. Accordingly, it is always good practice to prepare frozen stocks of newly established cell lines after as few passages as possible and to start large scale cultures for immunopurification from early passage cells.
} 
3. Remove supernatants, gently resuspend each cell pellet in approximately $10 \mathrm{ml}$ icecold PBS. Transfer cell suspensions from the $121 \mathrm{~L}$ centrifuge bottles into a total of $650 \mathrm{ml}$ conical plastic tubes, and fill each tube to $50 \mathrm{ml}$ with PBS.

4. Spin the cell suspensions $5 \mathrm{~min}$ at $1500 \mathrm{rpm}$ in the type JS4.2 rotor.

5. Remove supernatants, resuspend each pellet in $\sim 10 \mathrm{ml} \mathrm{PBS}$, transfer the resulting suspensions to $250 \mathrm{ml}$ conical tubes, and fill each tube to $50 \mathrm{ml}$ with PBS.

6. Spin the cell suspensions $5 \mathrm{~min}$ at $1500 \mathrm{rpm}$ in the type JS4.2 rotor.

7. Wash each pellet one more time with $\sim 50 \mathrm{ml}$ PBS.

8. Add $30 \mathrm{ml}$ hypotonic buffer to each of the two cell pellets. Gently resuspend the cells by blowing buffer onto them using a pipet. Do not draw the cells up into the pipet.

9. Incubate the cell suspensions for $15 \mathrm{~min}$. on ice.

10. Meanwhile, rinse the Dounce homogenizer and loose pestle with hypotonic buffer and keep cold on ice.

11. Transfer the cell suspension from one tube to pre-chilled $40 \mathrm{ml}$ Dounce homogenizer.

12. Homogenize in the Dounce homogenizer with $15-20$ gentle strokes of the loose pestle. Avoid generating foam.

13. Monitor cell disruption using Trypan-blue staining. Stop homogenizing when $\sim 80 \%$ of cells have been disrupted.

14. Repeat steps 11-13 until all of the remaining cell suspension has been homogenized.

15. Centrifuge at $20,000 \mathrm{rpm}$ for 20 minutes at $4^{\circ} \mathrm{C}$ in a Beckman type JA-20 rotor. Collect the supernatant, and add 0.11 volumes of Buffer $\mathrm{C}$, then keep on ice. This supernatant is the cytosolic fraction.

16. To remove contaminating cytosol and lipids that are stuck to the walls of tubes, layer $15 \mathrm{ml}$ of hypotonic buffer onto the nuclear pellets. Nuclei are very fragile at this point, so it is best to avoid resuspending them. Centrifuge at 5,000 rpm for 8 minutes at $4{ }^{\circ} \mathrm{C}$ in a Beckman type JA-20 rotor, and carefully remove the supernatants.

17. Add $5 \mathrm{ml}$ extraction buffer to one of the nuclear pellets, and gently pipet up and down. Transfer the resulting suspension onto the second nuclear pellet, and gently resuspend. Finally, transfer the pooled suspension to a clean graduated $15 \mathrm{ml}$ conical tube.

18. To estimate the volume of nuclear pellet contained in the suspension, measure the total volume of the suspension. Nuclear pellet volume $=$ the total volume of the suspension - $5 \mathrm{ml}$.

19. Transfer to a $70 \mathrm{ml}$ polycarbonate bottle for a Beckman type $45 \mathrm{Ti}$ rotor. Add additional extraction buffer to bring the total volume of the suspension to twice the nuclear pellet volume. This will bring the final $\mathrm{NaCl}$ concentration of the suspension to $0.3 \mathrm{M}$.

20. Pipet gently to generate a homogenous suspension. The suspension will become somewhat viscous at this stage due to salt-induced decondensation of chromatin. Decondensed chromatin can be easily sheared by over-vigorous mixing (i.e. 
vigorous pipetting, mixing, or vortexing). Avoid this, since the extract will contain a lot of contaminating DNA that can cause problems with subsequent purification steps if the chromatin becomes significantly sheared.

21. Place capped centrifuge bottle containing nuclear extract on a variable speed motorized tube rotator, and rotate end-over-end for at least 30 minutes at $20 \mathrm{rpm}$ at $4^{\circ} \mathrm{C}$ to extract nuclear proteins from chromatin.

22. Spin nuclear extract and $\mathrm{S} 100$ samples from step 14 at $35,000 \mathrm{rpm}$ for $1 \mathrm{hr}$ at $4^{\circ} \mathrm{C}$ in a Beckman type 45Ti rotor.

23. Collect the cleared supernatants from the nuclear and cytosolic fractions; these are the nuclear extract and S100 fractions, respectively.

\subsection{Immunoaffinity Purification of Epitope-tagged Proteins and Multi-protein Complexes}

Carry out all procedures in a $4{ }^{\circ} \mathrm{C}$ cold room or on ice unless otherwise specified. For trial immunopurification, use whole cell lysates prepared from cells grown to $~ 90 \%$ confluency in 1 or $210 \mathrm{~cm}$ dishes with $20 \mu \mathrm{l}$ packed bed volume of FLAG-M2 agarose immunoaffinity resin. For preparative immunopurification, use $5-6 \mathrm{ml}$ of nuclear extract or $8-10 \mathrm{ml}$ of cytosolic fraction (S100) prepared as described above ( 30-50mg total protein), with $100 \mu \mathrm{l}$ FLAG-M2 agarose. In addition, the immunopurification method described below can be used with starting fraction prepared by other protocols (but see Note 4). We have also successfully used the methods described here to purify epitope-tagged proteins and complexes through additional epitopes using the immunoaffinity resins and elution peptides listed in Table 1.

\subsubsection{Preparation of immunoaffinity beads}

1. Transfer at least 1.5 packed volumes of the amount of immunoaffinity resin required for the purification to a clean $1.5 \mathrm{ml}$ tube.

2. Add 10 volumes of binding buffer, and gently invert tubes several times until resin is resuspended into an uniform slurry with no clumps.

3. Centrifuge at $200 \times \mathrm{g}$ for $30 \mathrm{sec}$. It is important not to spin too hard or beads will become difficult to resuspend.

4. Carefully remove the supernatant without disturbing the packed agarose bed.

5. Repeat steps $2-4$ an additional 3 times.

6. Add enough binding buffer to make a $50 \%$ slurry of the immunoaffinity resin.

7. Beads should be stored on ice or at $4^{\circ} \mathrm{C}$ until use. Pre-equilibrated beads can be stored for up to 1 week.

\subsubsection{Immunoaffinity Purification from Nuclear Extract (Batch chromatography)}

1. Thaw nuclear extract. To avoid proteolysis or protein denaturation, it is important to keep the extract cold during the thawing process. Place tube on benchtop until frozen extract begins to thaw. Gently mix the frozen slurry by rocking the tube by hand until it is about two-thirds thawed, then lay it on a bed of ice or place it at $4^{\circ} \mathrm{C}$ until it is completely thawed.

\footnotetext{
${ }^{4}$ Carefully examine the components of buffers in the starting fractions used for immunopurification, since binding of individual antibodies to their epitopes can be dramatically and differentially affected by detergents, salts, reducing agents, and other buffer components. Antibody manufacturers often provide information about reagent compatibility, and this should be carefully considered.
} 
2. Spin the thawed extract for $15 \mathrm{~min}$ at $35 \mathrm{~K} \mathrm{rpm} 4^{\circ} \mathrm{C}$ in a Beckman type Ti70.1 rotor in an ultracentrifuge. Save several $50 \mu \mathrm{l}$ aliquots of the starting extract and keep on ice; these will be analyzed along with the final immunopurified material using western blotting or other assays to determine the efficiency of the purification.

3. Carefully transfer the cleared extract to a clean $15 \mathrm{ml}$ conical tube.

4. Add $200 \mu \mathrm{l}$ of the $50 \%$ slurry of pre-equilibrated immunoaffinity beads (equivalent to $100 \mu$ l of packed beads).

5. Incubate at $4^{\circ} \mathrm{C}$ for $4-12$ hours on a variable speed motorized tube rotator at $<20$ rpm (See Note 5).

6. Pellet the affinity matrix by centrifugation at $1,000 \mathrm{rpm}$ for 5 minutes at $4^{\circ} \mathrm{C}$ in a Beckman type JS4.2 rotor and J6 centrifuge or other low speed centrifuge.

7. Remove the supernatant, and save it for a second round of immunoaffinity purification.

8. To wash residual unbound proteins away from the immunoaffinity matrix, add $5 \mathrm{ml}$ of washing buffer to the beads, and incubate for 5 minutes at $4^{\circ} \mathrm{C}$ on a rocking mixer (such as an Adams ${ }^{\mathrm{TM}}$ Nutator Mixer).

9. Centrifuge at $1,000 \mathrm{rpm}$ for 5 minutes at $4^{\circ} \mathrm{C}$.

10. Carefully aspirate the supernatant without disturbing the resin.

11. Repeat steps $8-10$ an additional 4 times, for a total of 5 washes.

12. Spin the washed resin one more time at $1,000 \mathrm{rpm}$ for 5 minutes at $4^{\circ} \mathrm{C}$ to pack the beads and allow removal of remaining buffer.

13. Carefully remove the remaining buffer from the beads with a Pipetman or similar pipettor with a narrow tip.

14. Add $500 \mu$ l elution base buffer and transfer the immunoaffinity beads from the 15 $\mathrm{ml}$ tube to a new $1.5 \mathrm{ml}$ low binding microcentrifuge tube.

15. To recover any beads that were left behind, rinse the $15 \mathrm{ml}$ tube with an additional $500 \mu \mathrm{l}$ elution base buffer and add to the $1.5 \mathrm{ml}$ microcentrifuge tube from the previous step.

16. Centrifuge at $1,000 \mathrm{rpm}(200 \times \mathrm{g})$ for 1 minute in a microcentrifuge.

17. Remove and discard the supernatant.

18. To ensure removal of as much buffer as possible, centrifuge the washed resin one more time at 1,000 rpm for 1 minute in the microcentrifuge, and remove and discard any remaining liquid. To elute bound proteins, apply 1 packed bed volume $(100 \mu \mathrm{l})$ of elution buffer containing $200-500 \mu \mathrm{g} / \mathrm{ml}$ FLAG peptide to the immunoaffinity resin (See Note 6).

\footnotetext{
${ }^{5}$ The optimal length of time for incubation of cell extracts with immunoaffinity beads needs to be determined. Shorter incubation times most often yield immunopurified material with fewer contaminants; however, with some epitope tagged proteins, a longer incubation can increase yield

${ }^{6}$ Optimal elution peptide, buffer composition, and the temperature at which the elution step is performed need to be determined empirically. Researchers often use elution peptides containing either one or three copies of the epitope sequence (1x or $3 \mathrm{x}$ epitope peptide, respectively). In our experience, 1x peptides are usually sufficient; in addition, they are less expensive and often give rise to immunopurified fractions with fewer contaminants. In initial trials, we typically test elution buffers containing $200 \mu \mathrm{g} / \mathrm{ml}$ or $500 \mu \mathrm{g} /$ $\mathrm{ml}$ of $1 \mathrm{x}$ epitope peptide. If satisfactory yields are not obtained using $1 \mathrm{x}$ epitope peptide, we then try elution buffers containing $3 \mathrm{x}$ epitope peptide. We usually obtain good yields of FLAG-tagged proteins when elutions are performed at $4^{\circ} \mathrm{C}$; however, yields of HA-, cMyc-, and V5-tagged proteins are usually better when elutions are performed between about $20^{\circ} \mathrm{C}$ and $37^{\circ} \mathrm{C}$.
} 
19. Incubate at $4^{\circ} \mathrm{C}$ on the rocking mixer for at least 30 minutes.

20. Centrifuge at 1,000 rpm for 1 minute. IMPORTANT: The supernatant from this spin contains immunopurified protein or protein complexes that have been eluted from the resin.

21. Remove the snap-off tip from an empty Micro Bio-Spin ${ }^{\circledR}$ chromatography column, and set the empty column on top of a new $1.5 \mathrm{ml}$ low binding microcentrifuge tube (Figure 3).

22. Carefully transfer the supernatant from step 21 into the empty Micro Bio-Spin ${ }^{\circledR}$ column on the microcentrifuge tube.

23. Centrifuge at $1,000 \mathrm{rpm}$ for 1 minute. The purified protein fraction will flow through the empty column into the microcentrifuge tube, and any remaining immunoaffinity resin will be filtered out of the purified protein fraction and will be retained in the column.

24. Repeat elution steps 18-23 an additional two times to elute additional protein from the immunoaffinity resin. Save the eluted fractions separately as "E1, E2, and E3."

25. Snap freeze immunopurified samples (E1, E2, and E3) in liquid nitrogen and store at $-80^{\circ} \mathrm{C}$ for further analysis (see Note 7 ). At this time also freeze the aliquots of extract reserved at the beginning of the purification. Many proteins or protein complexes are unstable to repeated freeze-thaw, so it is a good idea to divide purified protein fractions into multiple small aliquots prior to freezing.

\subsubsection{Purification of epitope tagged proteins from the cytosolic fraction (S100)}

1. Thaw the $\mathrm{S} 100$ fraction, and spin at $35,000 \mathrm{rpm}$ at $4{ }^{\circ} \mathrm{C}$ for $15 \mathrm{~min}$ in a Beckman type Ti70.1 rotor.

2. Transfer to a $15 \mathrm{ml}$ conical tube.

3. To minimize non-specific protein binding to the immunoaffinity resin, pre-clear the S100 fraction by incubating it with Sepharose 4B $(300 \mu l$ packed beads per $10 \mathrm{ml}$ $\mathrm{S} 100$ fraction) for $10 \mathrm{~min}$ at $4^{\circ} \mathrm{C}$ with rotation on a variable speed motorized tube rotator at $20 \mathrm{rpm}$. Keep several $50 \mu \mathrm{l}$ aliquots of the $\mathrm{S} 100$ fraction for further analysis.

4. Pellet Sepharose 4B resin by centrifugation at $1000 \mathrm{rpm}$ in the Beckman type JS4.2 rotor, and transfer the supernatant to a new $15 \mathrm{ml}$ conical tube.

5. Repeat steps 3 and 4 an additional 2 times. The final supernatant is the pre-cleared S100 fraction.

6. Spin the pre-cleared $\mathrm{S} 100$ at $35,000 \mathrm{rpm}$ in Beckman type Ti70.1 rotor for 15 min at $4^{\circ} \mathrm{C}$.

7. Carefully collect the supernatant, and transfer to a $10 \mathrm{ml}$ disposable syringe attached to a glass fiber pre-filter disc (Millex-AP).

8. Filter the $\mathrm{S} 100$ fraction through the glass fiber pre-filter disc into a new $15 \mathrm{ml}$ conical bottom tube to capture contaminating lipids and minimize carryover of beads from the pre-clearing steps.

${ }^{7}$ Following peptide elution from immunoaffinity beads, epitope-tagged proteins or protein complexes will be contaminated with a significant amount of the elution peptide. If necessary, desalting chromatography with resins such as Sephadex G-25 or G-50 (GE Healthcare Life Sciences) can be performed to remove peptide from immunopurified proteins. 
9. Proceed to immunoaffinity purification using the procedures described in section 3.3.2, steps 4 to 26 .

\subsubsection{Immunoaffinity Purification Using Column Chromatography-}

Immunoaffinity purification using column chromatography can be used as an alternative to the batch purification method described above. Advantages of column purification methods include (i) ease of scale-up and (ii) avoidance of non-specific trapping of denatured or aggregated proteins present in the lysate.

1. Prepare nuclear extract samples for immunoaffinity column chromatography using steps 1 and 2 of Protocol 3.3.2. Prepare S100 fractions using steps 1 to 8 in Protocol 3.3.3.

2. Use $100 \mu \mathrm{l}$ immunoaffinity agarose per approximately $30 \mathrm{mg}$ of nuclear extract or S100 protein.

3. Pack immunoaffinity resin into a suitable column by gravity flow. We use Bio-Rad Poly-Prep ${ }^{\circledR}$ disposable chromatography columns for resin volumes up to $\sim 1 \mathrm{ml}$. Do not allow the resin to become dry.

4. Float a glass fiber filter on top of the bed, and gently layer the cleared nuclear extract or S100 on top of the resin.

5. Allow the column to flow at $10-15$ column volumes per hour until all of the nuclear extract or $\mathrm{S} 100$ has been loaded on to the column.

6. Collect the flow-through fractions and reload them on to the resin. Repeat this process until all of the nuclear extract or S100 has been passed through the column 5 times.

7. Wash the resin with 30 bed volumes of washing buffer at the maximum flow rate attainable with gravity flow $(\sim 50 \mu \mathrm{l} / \mathrm{min}$ for $100 \mu \mathrm{l}$ resin)

8. Stop the flow. Gently apply $5-6$ bed volumes of elution buffer on top of the resin. Incubate for 30 minutes at $4^{\circ} \mathrm{C}$.

9. Allow the column to flow at $\sim 10$ column volumes per hour. Collect 10 fractions of 1 bed volume each, and assay for the presence of the desired protein by western blotting or other suitable assays. See Note 7.

\section{Acknowledgments}

Work in the authors' laboratory is supported by grant GM41628 from the National Institute of General Medicine and the Stowers Institute for Medical Research.

\section{References}

1. Jarvik JW, Telmer CA. Epitope tagging. Annu Rev Genet. 1998; 32:601-618. [PubMed: 9928493]

2. Einhauer A, Jungbauer A. The FLAG peptide, a versatile fusion tag for the purification of recombinant proteins. J Biochem Biophys Methods. 2001; 49:455-465. [PubMed: 11694294]

3. Field, Jeffrey, et al. Purification of a RAS-responsive adenylyl cyclase complex from Saccharomyces cerevisiae by use of an epitope addition method. Mol Cell Biol. 1988; 8:2159-2165. [PubMed: 2455217]

4. Ellison MJ, Hochstrasser M. Epitope-tagged ubiquitin. A new probe for analyzing ubiquitin function. J Biol Chem. 1991; 266:21150-21157. [PubMed: 1718971]

5. Southern, James A., et al. Identification of an epitope on the $\mathrm{P}$ and $\mathrm{V}$ proteins of simian virus 5 that distinguishes between two isolates with different biological characteristics. J Gen Virol. 1991; 72(Pt 7):1551-1557. [PubMed: 1713260] 
6. Sato, Shigeo, et al. A set of consensus mammalian mediator subunits identified by multidimensional protein identification technology. Mol Cell. 2004; 14:685-691. [PubMed: 15175163]

7. Takahashi, Hidehisa, et al. Human mediator subunit MED26 functions as a docking site for transcription elongation factors. Cell. 2011; 146:92-104. [PubMed: 21729782]

8. Mortensen RM, Kingston RE. Selection of transfected mammalian cells. Curr Protoc Mol Biol. 2009; 86:9.5.1-9.5.13.

9. Manley, James L., et al. DNA-dependent transcription of adenovirus genes in a soluble whole-cell extract. Proc Natl Acad Sci U S A. 1980; 77:3855-3859. [PubMed: 6933441]

10. Dignam JD, Lebovitz RM, Roeder RG. Accurate transcription initiation by RNA polymerase II in a soluble extract from isolated mammalian nuclei. Nucleic Acids Res. 1983; 11:1475-1489. [PubMed: 6828386]

11. Abmayr, Susan M., et al. Preparation of nuclear and cytoplasmic extracts from mammalian cells. Curr Protoc Mol Biol. 2006; 75:12.11.11-12.11.10. 
Construct expression vector

e.g. FLAG, HA, cMyc, V5 encoding epitope tagged protein.

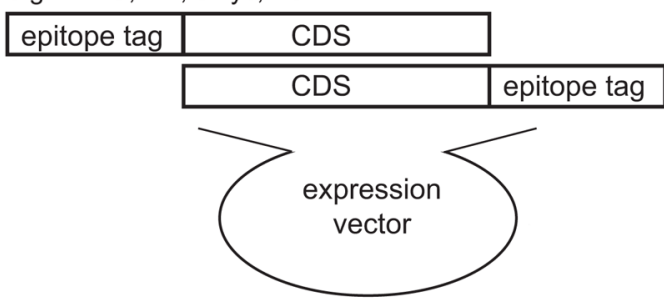

Generate stable cell line

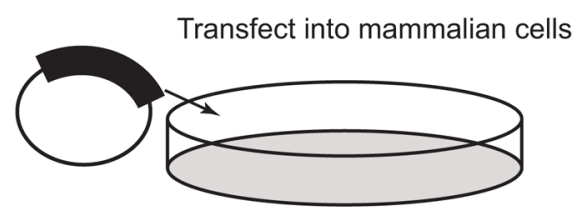

Select clonal cells stably expressing epitope tagged protein



Amplify stably expressing cells

Purify epitope tagged protein and its associated protein complex

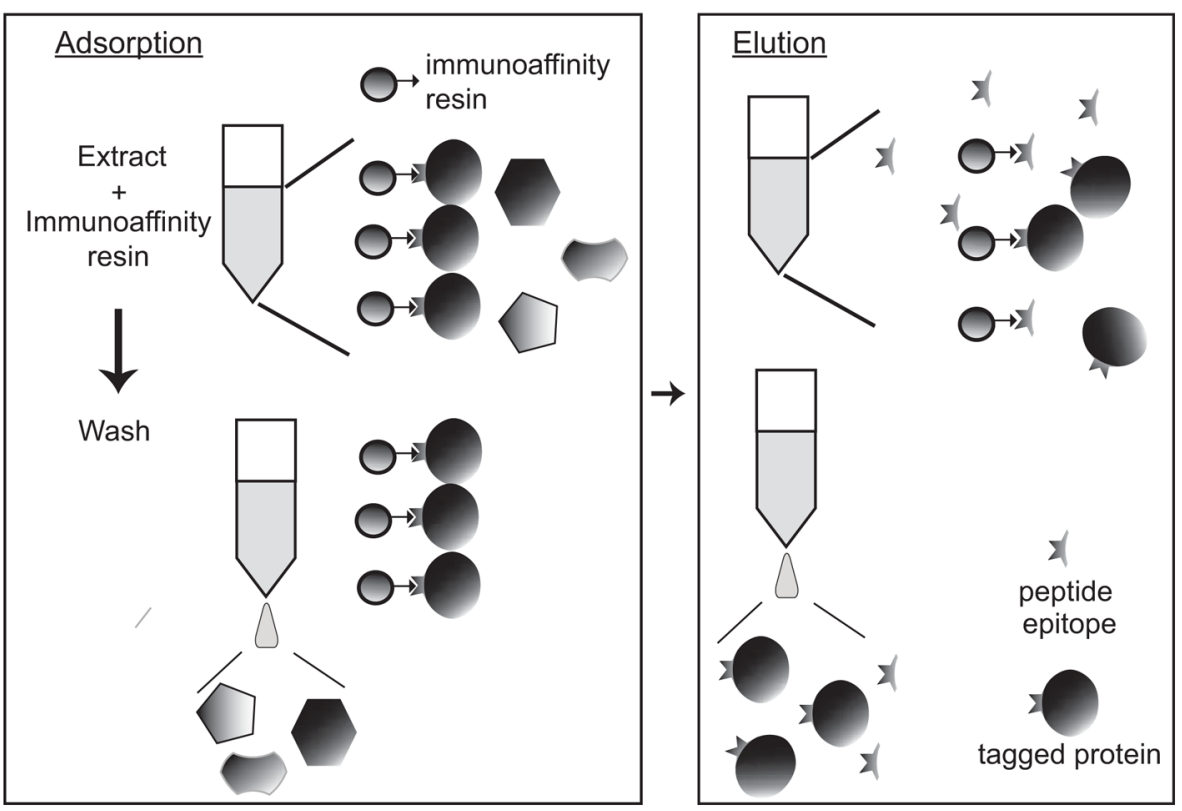

Figure 1.

Scheme For Immunoaffinity Purification of Protein Complexes 


\section{FLAG M2 Immunoaffinity \\ Purified Mammalian Mediator Complexes}

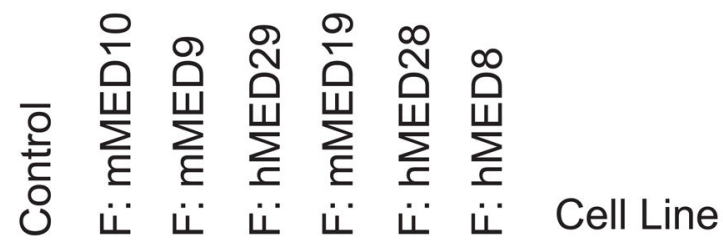

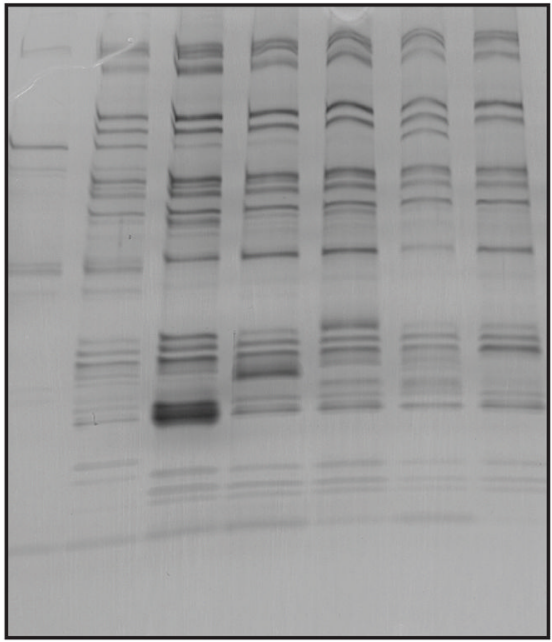

Figure 2.

Immunoaffinity Purified Mammalian Mediator Complex From HeLa S3 Nuclear Extract Through FLAG-tagged Mediator Subunits. 


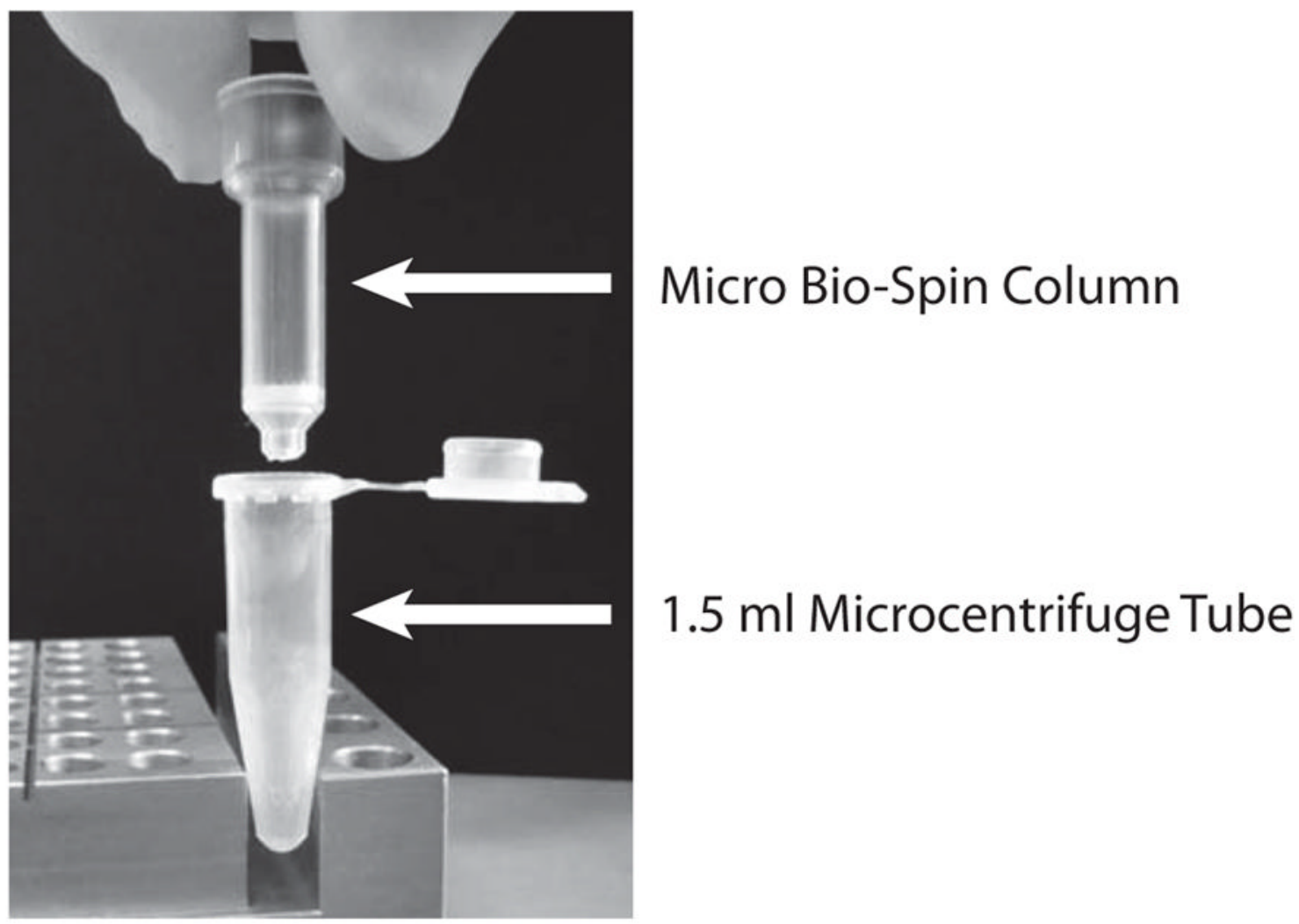

Figure 3.

Micro Bio-Spin Chromatography Column Used to Remove Residual Beads From Immunoaffinity Purified Fractions 


\section{Table 1}

Useful Epitope Tags and Resins for Immunoaffinity Purification

\begin{tabular}{llll}
\hline Tag & Epitope peptide sequence & Affinity resin & Binding specificity \\
\hline FLAG & DYKDDDDK & a-FLAG M2 agarose (SIGMA) & N, Met-N, Internal, C \\
HA & YPYDVPDYA & a-HA agarose (HA-7, SIGMA) & N, C \\
& & a-HA agarose (HA.11, Covance) & N, Internal, C \\
cMyc & EQKLISEEDL & a-cMyc pAb agarose (SIGMA) & N, C \\
& & a-cMyc agarose (9E11, Santa cruz) & N, C \\
V5 & \multirow{2}{*}{ GKPIPNPLLGLDST } & a-V5 agarose (V5-10, SIGMA) & N, C \\
\hline
\end{tabular}

Elution from antibody affinity resins is typically performed using peptides composed of 1 or 3 consecutive repeats of the epitope sequence. 
Table 2

Gene Transfer Systems for Generating Stable Mammalian Expression Cell Lines

\begin{tabular}{|c|c|c|}
\hline Gene Transfer System & Advantage & Disadvantage \\
\hline \multicolumn{3}{|l|}{ 1. Plasmid based gene transduction } \\
\hline $\begin{array}{l}\text { (A.) Transfection/Random integration (e.g. Calcium } \\
\text { phosphate, Lipofection, Electroporation) }\end{array}$ & $\begin{array}{l}\text { Simple procedure, Wide range of } \\
\text { cell types }\end{array}$ & $\begin{array}{l}\text { Low efficiency, } \\
\text { Potential multiple integration }\end{array}$ \\
\hline $\begin{array}{l}\text { (B.) Transfection/DNA recombinase mediated integration } \\
\text { (e.g. Flp-In, cre- loxP, piggy-Bac transposon system) }\end{array}$ & $\begin{array}{l}\text { Simple procedure, Single copy of } \\
\text { the integration of gene of interest at } \\
\text { defined locus }\end{array}$ & Limited host cells \\
\hline \multicolumn{3}{|l|}{ 2. Virus mediated gene transduction } \\
\hline $\begin{array}{l}\text { Retrovirus or Lenti virus mediated gene integration (e.g. } \\
\text { MMLV, MMSV, HIV) }\end{array}$ & Wide range of cell types & $\begin{array}{l}\text { Virus handling technique is required, } \\
\text { Random and potential multiple } \\
\text { integration }\end{array}$ \\
\hline $\begin{array}{l}\text { DNA virus intection (e.g. adenovirus, EB virus, Vaccinia } \\
\text { virus) }\end{array}$ & & $\begin{array}{l}\text { Limited host cells, } \\
\text { DNA is not integrated into genome. }\end{array}$ \\
\hline
\end{tabular}

